\title{
Policy Changes, Marketization Trends, and Spatial Dispersion in European Higher Education: Comparing Public and Private Sectors
}

\section{Introduction}

Higher education institutions (HEIs) live in a period of profound transformation, which has been reshaping their mission, their organizational structures, and the way they interact with society (see, among others, Weisbrod et al., 2008 and Geiger, 2004). The magnitude and inherent tensions associated with these changes have created a context that many consider to be a climate of crisis in higher education (Readings, 1996; Slaughter and Leslie, 1997; Bok, 2003). This has been particularly significant in the European case, not only because universities have a long historical and symbolic presence in the life of the continent, but also because until a few decades ago they were closely tied with the nation-state fabric (Neave, 2012; Neave and Van Vught; 1991). However, decades of expansion in this sector have challenged the status quo in European systems and have led many countries to rethink their approach to higher education (Palfreyman and Tapper, 2009; Teixeira, 2009), namely regarding the modes of regulation and provision of higher education to a much expanded and more diverse student population (Scott, 1995; Trow, 2010).

Mass higher education has stimulated a debate about the means of catering for a growing and increasingly diverse population in a more economic and efficient way. A major policy response to those challenges has been the adoption of market elements in higher education systems (Teixeira et al, 2004; Regini, 2011). The introduction of market forces has ranged from important changes in the way public institutions are funded, managed and regulated, notably by promoting the adoption of more managerial types of behaviour (Morphew and Eckel, 2009) to the development of greater inter-institutional competition and the emergence 
of private higher education provision. ${ }^{1}$ These changes were often stimulated by public policies (Le Grand, 2007) and aimed at enhancing choice for students and families (Jongbloed, 2006). It was also expected that a more competitive educational market would contribute to more efficient behaviour by universities and colleges, namely among public institutions (Pollitt and Bouckaert, 2011).

These changes have been a theme of intense discussion in higher education policy and research, though there has been limited reflection on their potential implications from a regional perspective. Thus, in this text we will give particular attention to the possible links between those trends towards greater marketization - and the consequent greater role of private providers - and the spatial distribution of higher education in Europe. We intend to reflect about the way this changing context may affect the regional distribution of public and private higher education across Europe and create greater inequalities in the regional access to higher education.

The remaining sections of this paper are structured as follows. In the next section, we analyse the changing context in European higher education policy and briefly present the trend towards greater market regulation in European higher education. In Section 3 we reflect about the potential impacts of those marketization trends on institutional behaviour, paying particular attention to some of the possible implications regarding HEIs' regional role and distribution. Then, in Section 4 we provide information about the data and methodology used for the empirical analysis presented in the paper. In Section 5, we analyse the patterns of

\footnotetext{
${ }^{1}$ The classification of an institution as private is a complex matter and can vary according to the criteria used (see Williams, 1991 and Geiger, 1986). Thus, some institutions may be private from an ownership point of view, but may be publicly funded. Other countries also distinguish between public and state-owned institutions. In this text we use the term private institutions to refer to those HEIs that are not only privately owned, but also privately funded. These private institutions can be not-for-profit or for-profit, though this is less the case in the European case, due to legal restrictions founded on political and social mistrust towards the idea of having business ventures in educational matters (see Teixeira, 2009).
} 
geographical diversification between public and private sectors across a sample of European countries and we complete this with an analysis of the differences in the programmatic diversification observed between HEIs located in capital and non-capital regions. The text concludes with a reflection about the way current policy changes in European higher education may be shaping the spatial distribution of public and private HEIs and changing the profiles of the public and private sectors.

\section{Policy Changes and Market Regulation in European Higher Education}

Recent decades have brought about an unprecedented expansion of higher education across Europe that has consolidated a pattern of mass access and created important policy challenges (Scott, 1995; Trow, 2010). Higher education has become a large enterprise with European systems evolving from a small group of elite institutions into large-scale systems with dozens of institutions that are supposed to cater for a much larger and more diverse student population - for instance, regarding their gender, age, geographic origin, ethnic and socio-economic background. The development of the sector was also associated with an expansion of the types of higher education providers - besides the more traditional preexisting elite ones, more vocational forms of higher education have gained an increasing relevance. As a result, the massification of higher education meant not only growing rates of enrolment, but also more heterogeneous and complex higher education systems, with growing competition pressures between institutions.

Hence, it was no longer possible, or at least advisable, for most governments to maintain a pattern of detailed regulation of higher education institutions (Neave and van Vught, 1991). Governments needed to explore new forms of steering that could be more effective within the new context of mass higher education (Amaral et al, 2002). Moreover, they needed to explore which options were available to steer those still heavily subsidised universities and colleges 
in directions that would comply with the public interest. Thus, in recent decades, we have seen in many European countries a move away from old patterns of tight state regulation and bureaucratic control to a mode of regulation that keeps a significant degree of government intervention, but that has introduced significant institutional autonomy and delegated a significant part of the daily management to the HEIs.

In this context we have observed a change in the traditional role of government in many European countries (Neave and Van Vught 1991). The authority of government, its mode of collective decision making, its use of command and control steering approaches, the budget mechanism and the monopoly of state-run HEIs have been increasingly questioned. From a system perspective, the aim has been to move from a 'state control model' to a 'state supervising model' (Van Vught, 1989), according to which the state designs a framework of rules and policy objectives for the system as a whole, while institutions have the freedom and the responsibility to set their own missions, priorities and programmes, decide on their own organization and internal management, manage their own estate and physical assets, and recruit, train and incentivise their own staff. In return, universities are to be held accountable to society for their results, including the cost-efficiency and effectiveness by which the desired outcomes are achieved. Hence, the state's role became 'evaluative' rather than directive (Neave, 2012). As a consequence, new and less hierarchical relationships between government and higher education providers have emerged, and governments and institutional leaderships have started to experiment with more market-oriented steering and more complex organizational models (see De Boer et al, 2009).

The recent expansion of higher education has also coincided with a period of increasing constraints on public expenditure, which has affected education in general and higher education in particular (Barr, 2004; Johnstone and Marcucci, 2010). Those financial constraints cannot be dissociated from the new political mood, characterized by the growing 
influence of an ideological agenda based on increasing liberalization, which has unleashed market forces and restrained government intervention in various areas of social expenditure (Pollitt and Bouckaert, 2011; Slaughter and Leslie, 1997). The reduction of government intervention and the promotion of competition and private initiative were expected to enhance the trends towards greater diversification, and to motivate the (now increasingly autonomous) European universities to become more adaptable and to find ways of satisfying both student and labour market demands more effectively (Regini, 2011; Teixeira et al., 2004).

Thus, recent years have seen the strengthening of a discourse that emphasizes the advantages of market forces over public regulation in many sectors. Higher education has not been an exception to that trend. The traditional public ethos of many higher education systems and institutions has been questioned and eroded, and the political discourse has given growing visibility to the role of markets and market mechanisms in higher education (Bok, 2003). Besides, the political and social environment in which higher education is embedded has tended to emphasize the advantages of market forces, particularly competition and privatization, vis-à-vis the shortcomings of public intervention in higher education (Slaughter and Leslie, 1997; Morphew and Eckel, 2009). Thus, HEIs have become more exposed to the fate of the competition, creating a greater room for segmentation and stratification.

These changes have been particularly controversial and complex in Europe, since in this region there is a prevailing vision of higher education as a bastion of public service and that, regardless of the current difficulties, should remain to be the case. Universities have been regarded for long as a public responsibility and many European countries regard with scepticism the possibility that, like in other parts of the world, market forces and private ownership may make significant inroads in this sector (Altbach, 1999; Teixeira, 2009). However, in recent times, European governments have been more willing to introduce market 
elements in the regulation of higher education and to allow the development of its privately funded provision.

The growing influence of market mechanisms in higher education has been manifested in various and complex ways (Regini, 2011; Teixeira et al., 2004). One of the main dimensions through which marketization has mostly pervaded HEIs has been through funding. Although higher education funding in many European countries continues to take place through the allocation of grants and funding formulas, which give institutions greater freedom to administer the resources assigned to them by public authorities, the criteria to determine the distribution of funding among HEIs have increasingly relied on performance comparisons at the institutional-level, which resulted in a growing popularity of competitive funding for teaching and research (Herbst, 2006; Geuna, 2001). This has created greater room for differentiation among HEIs since neither all institutions are likely to perform equally, nor the indicators used are neutral regarding institutional differences. Some institutions are likely to benefit more than others, not only owing to their internal strengths, but also because their mission and priorities may fit better the profile underpinning those indicators.

Notwithstanding the persistent dominance of public funding for most European universities, private sources have become increasingly important and this is likely to be reinforced in the near future. This financial diversification was associated with changing attitudes, with HEIs increasingly being encouraged to regard students as consumers and to nurture commercial links with private companies (Slaughter and Leslie, 1997; Regini, 2011). However, not all HEIs face the same opportunities and regional differences may be particularly relevant in this respect, since those located in wealthier and more dynamic economic regions may enjoy greater opportunities for collaboration and additional revenues. Once again, the potential for greater stratification and differentiation seems apparent. 


\section{European Higher Education Institutions between the State and the Market}

\section{- Some regional implications}

The recent wave of policy reforms favouring market regulation has had important consequences for the internal life of HEIs. Thus, in recent years, higher education's governance has increasingly being seen through the "Corporate-market" lens (Middlehurst and Teixeira, 2012). In governance terms, 'corporate' implies more executive management control within institutions, with less 'administration' and fewer committees, combined with a board of trustees or governors with external lay (i.e. non-academic) representation that will hold the executive to account. The genesis of this perspective is modern, arising from neoliberalism and New Public Management ideologies (Pollitt and Bouckaert, 2009) and the rise of quasi-markets in higher education, reflecting wider trends in the public sector (see Le Grand and Bartlett, 1993; Le Grand, 2007). According to these views, HEIs should be run more like corporations in order to increase their efficiency and productivity.

However, the growing influence of market mechanisms in higher education and the marketization of institutional behaviour should not distract us from the fact that governments continue to have a significant role in the regulation of public HEIs and in conditioning their autonomy. The role of the government is even underlined in the way it has administered the growing trends towards marketization (Teixeira et al, 2004; Regini, 2011). The encouragement of market-like coordination has led to some kind of paradox. The fact that institutions were granted enhanced autonomy from state coordination meant that they could be more responsive to market needs and demands. Thus, European HEIs need to balance multiple and often contradictory demands, since they face a coexistence of government and market regulation, and need to balance the pursuit of public missions with their responsiveness to market stimuli. This has been discussed on several instances, but its 
implications regarding the regional dimension of higher education has thus far received limited attention.

One of the major outcomes of the massive expansion of higher education across Europe was the expansion of its regional coverage, with many new institutions being established in regions that were historically deprived from higher education provision. The expansion of higher education has changed the regional distribution of HEIs, with public authorities trying to promote a more regionally balanced access to post-secondary education and using these institutions as tools to promote regional development and economic growth. However, the growing pervasiveness of efficiency and managerial concerns in higher education policy has created important tensions in this respect. On the one hand, the rising cost of higher education has led many governments to become more careful about additional expansion and to consider a growing concentration of resources in a few institutions and locations in order to do some savings. This has made some of the more recently established and peripheral institutions more vulnerable to the emerging modes of public funding and support. On the other hand, higher education continued to be regarded as a major tool for the promotion of regional development, especially in more peripheral areas (for a discussion about the role of HEIs as a policy instrument for regional development see for instance, Andersson et al., 2004; Charles, 2006; Sterlacchini, 2008). Thus, any retrenchment of public higher education was regarded as potentially very damaging to those regions already struggling with depopulation and a decline of their economic attractiveness.

One development that may be significant in this respect refers to the increasingly popular so-called excellence initiatives, according to which only a few HEIs are promoted to that status - given the positive influence for a university to enter the top of the rankings in their ability to attract more students and external funding (Hazelkorn, 2007) - instead of distributing the resources more evenly. In those countries where there were significant policy 
initiatives (namely in Germany, France, and Spain), the regional disparities and the way those funding instruments could contribute to greater (in)equalities have been the focus of significant debate and controversy, especially due to the tendency to concentrate funding in a few institutions and regions at a time of increasingly scarce public funding for higher education (see Kehm, 2006 and Rubiralta and Delgado, 2010).

Moreover, the growing marketization of higher education systems and organizational behaviour may have important implications regarding the regional dimension of higher education provision. Several observers have argued that the stimulus towards greater responsiveness to external needs and demands could make some institutions to develop a bias towards short-term strategies (Bok, 2003). This emphasis on a business-like approach could be damaging to some activities that may be less financially attractive or less valued from a reputational point of view (Geiger, 2004). If pushed too far, marketization may alter fundamentally the character of a university, which is primarily engaged in instruction and research, as some HEIs may be less likely to pursue a distinctive regional contribution inasmuch as it may not be sufficiently rewarded by competitive national reward mechanisms (Shattock, 2008).

This pro-business approach of public higher education has been reinforced not only by an emphasis on market regulation, but also by the recent development of private higher education in many European systems. ${ }^{2}$ Although higher education institutions were recognized as a peculiar type of organization (Winston, 1999), policy makers have been keen to promote a more managerial behaviour by HEIs (Amaral et al, 2003). Moreover, in several

\footnotetext{
${ }^{2}$ Although by mid-twentieth century private institutions were absent from most European countries (and even when they existed their relative size was small in comparison to the public sector), recent years have seen an expansion of this sector in many parts of Europe. The major surge in private institutions in Europe has emerged in that part of the continent that for several decades has prevented its establishment. With the collapse of the communist regimes towards the end of the twentieth century, private higher education became a significant feature of many systems in Central and Eastern Europe (Wells et al., 2007).
} 
countries the promotion of private institutions has been regarded as an instrument to foster the assimilation of more efficient practices among public HEIs through a better management of resources (Tierney, 1998).

The arguments used in favour of the development of private higher education were not only related to issues of internal efficiency, but also to the debates about the degree of external efficiency of the higher education system (Levy, 2002). The private sector was supposed to demonstrate an increased capacity for exploring new market opportunities and for occupying market niches, by using its higher administrative flexibility and financial motivation. Private and private-like institutions - meaning those institutions treated as if they were privately-owned - were believed to promote a better balanced supply of higher education from a geographical and disciplinary perspective. A similar rationale was present as regards labour market demands, as the expected greater responsiveness of private-type HEIs was regarded as a powerful force driving institutions to supply qualifications more suitable to labour market needs. Accordingly, the changes aiming at strengthening market forces and a greater role of private initiative in higher education were expected to favour the emergence of a more innovative behaviour among public institutions as well (Geiger, 1986).

Thus, it is relevant to know more about the regional profile of public and private higher education, and the extent to which the marketization of the public sector and the emerging private institutions may be affecting regional diversity in European higher education. Recent research has raised serious doubts about the effectiveness of market competition in promoting a more diverse programme supply in higher education (Rossi, 2009; Teixeira et al., 2012a, 2012b; Welch, 2007). It is interesting to see how the current policy context in European higher education and the growing marketization may have been shaping the regional distribution of higher education supply across Europe. Notably, it will be interesting to see whether the distribution of the public and private sector are similar or if private HEIs present 
a different regional profile, which may reflect a greater responsiveness to market stimuli and to the concentration of population and wealth.

\section{Research Design}

From the above discussion, we document a great need for more systematic research about the commonalities and potential effects of the development of public and private higher education in Europe. In this article, we will focus on studying the relationship between this changing public-private mix across European higher education and patterns of regional diversification in higher education. In the following sections we analyse the patterns of spatial diversification between these two sectors across a sample of European countries and examine the extent to which the programmatic supply differs between capital and non-capital regions.

\section{Description of the data}

In order to study the public-private mix and the spatial diversification of HEIs in Europe, we use data collected through a recent large European project - the EUMIDA Project, carried out under the European Commission (Directorate General [DG] Research, DG Education and Culture, and EUROSTAT). Data collections were performed at the country level (EUMIDA, 2010), with the support of national official statistical agencies, and included a total of 1518 public and 931 private HEIs in the academic year of 2008/09. ${ }^{3}$ More detailed data were

\footnotetext{
${ }^{3}$ In this study we have classified institutions as public or private according to their legal ownership and sources of funding. Following the criteria established by the EUMIDA project, we have considered the so-called government dependent institutions as public, since this refers to institutions that are not necessarily state-owned
} 
gathered in a second phase of the project, which is particularly focused in research-active institutions (RAIs) (1213 public and 191 private). ${ }^{4}$ Data cover HEIs from 27 countries: the European Union member states (excluding Denmark, France and Croatia) plus Norway and Switzerland.

Table 1 provides a general overview of the set of countries analysed. Focusing on European RAIs, we observed that public HEIs represent the great majority of institutions in almost all countries, although there are a few exceptions. In terms of enrolled students in 2008, only Cyprus presented a relative superiority of the private sector, confirming that public HEIs overall tend to be larger than their private counterparts. There are a significant number of countries where the private sector was almost non-existent among RAIs, both in terms of institutions and enrolments (e.g. Czech Republic, Finland, Greece, Ireland, among others). ${ }^{5}$ We can also see from Table 1 that, when comparing the distribution of students and institutions between capital and non-capital regions, in most of the countries the proportion of students in the private sector is smaller in the non-capital regions, suggesting a higher relative importance of this sector in the capital regions of Europe. ${ }^{6}$

(Table 1 here)

but are treated as belonging to the public sector, most notably regarding funding and other regulations. Private institutions thus correspond to those HEIs that are not only privately owned, but also privately funded.

${ }^{4}$ RAIs correspond to HEIs that fulfil at least three out of the following six criteria: (1) the existence of an official research mandate; (2) the existence of research units institutionally recognized; (3) the inclusion in the R\&D statistics as sign of institutionalized research activity; (4) the award of doctorates or other ISCED Level 6 degrees; (5) the inclusion of research in the set of strategic objectives and plans; and (6) the availability of regular funding for research projects, either from public agencies or from private companies (EUMIDA, 2010).

${ }^{5}$ In the case of Spain, although there are private institutions, the national sources did not report data on this sector. Although we could have used data made available from other sources, for reasons of consistency we have refrained from doing so in this analysis.

${ }^{6}$ We define "capital regions" as the NUTs II region where the capital of each country belongs to. All other NUTs II regions were classified as "non-capital regions". 
Figure 1 depicts the relative weight of RAIs in total enrolments in the public and private sectors of each country. As expected, the public sector is much better represented than the private sector among this subset of institutions. This corresponds to the widespread perception in many European countries that, for a variety of reasons, private HEIs give a lower priority to research activities. Paramount among these reasons seem to be financial factors, as research activity - especially basic research - is normally regarded as having a long-term return and a low institutional financial reward, despite its often high social value (Geiger and Sá, 2008). Since in most countries private institutions have limited access to public funding for research, they have to fund those activities themselves. Thus, when some private institutions develop research activities, it is based on cross-subsidization from teaching funds and it is mainly to enhance their prestige and attain some degree of academic legitimacy, as an instrument of social and political recognition (Levy, 2002; Slantcheva and Levy, 2007). Part of the reason for this low research profile in the private sector has also to do with staff issues, since many private institutions rely strongly on part-time staff (Levy, 2006). Not only do part-time staff cost less, as they also provide a more flexible coststructure that may help the institution to adapt to changes in student demand.

(Figure 1 here)

\section{Methodological Issues}

In this paper, we are interested in analysing the differences between public and private higher education sectors regarding, first, the geographical distribution of HEIs, and second, their programmatic supply across the different regions of the country. A sector (i.e., public or private) will be more (or less) spatially diversified if the regions covered are wider (or 
narrower) relative to the overall possibilities. Similarly, regarding the programs offered by each sector in each region (capital/non-capital), diversity will be wider (narrower) the larger (smaller) the range of educational fields offered.

To measure the spatial/geographic diversity for each country, we use data on the total number of enrolled students in each sector, disaggregated by their NUTS II location. ${ }^{7} \mathrm{We}$ compute a "diversification index" for each sector $j$ (public or private), based on the inverse of the Herfindhal-Hirschman index - commonly used in Industrial Organization research to measure market concentration (Pepall et al., 2008) - as indicated below:

Spatial Diversification Index ${ }_{j}=\frac{1}{\Sigma \mathrm{i}(\mathrm{xj} / \mathrm{Xj})^{2}}$,

where $x_{j i}$ is the total number of enrolled students in sector $j$ and in NUTS II region $i$, and $X_{j}$ corresponds to total enrolments in sector $j$. This diversification index shows how widespread or concentrated the enrolments in each sector are across the different regions in each country. Due to the sensitivity of the index to the size of the sectors and to the existence of a different number of NUTS II regions for each country $(n)$, this index is normalized in order to take values in the range $[0,1]$ as follows:

Normalized Spatial Diversification Index ${ }_{j}=\frac{(\text { Spatial Diversification Indexj-1) }}{n-1}$.

We then complement our analysis of spatial diversification by describing the different programmatic offer of public and private HEIs located in the capital and non-capital regions.

\footnotetext{
${ }^{7}$ For HEIs reporting to be present in more than one region (and due to lack of information regarding HEIs' identity), we considered that the total number of enrolled students was equally distributed among the two or more regions reported. We believe that this simplifying assumption does not have significant implications for our results, given the few cases of HEIs with multiple locations in our dataset.
} 
To quantify programmatic diversity, we use data on total enrolments, disaggregated by sector $j$ (public or private), region $i$ (capital or non-capital) and educational field $k .^{8}$ Accordingly, for each country, a Programmatic Diversification Index) for each pair $(j, i)$ is computed as follows:

Programmatic Diversification Index ${ }_{j, i}=\frac{1}{\Sigma \mathrm{i}(\mathrm{xjik} / \mathrm{Xji})^{2}}$,

where $x_{j i k}$ is the total enrolment in sector $j$, region $i$ and educational field $k$, and $X_{j i}$ corresponds to total enrolments in sector $j$ and region $i$. This index is also normalized using an equivalent rule to that presented in equation (2), with $n$ now being equal to eight - the number of different educational fields.

\section{Spatial Diversity in European Higher Education}

Before proceeding with the analysis of spatial and programme diversity, we present a brief analysis of the data regarding the regional distribution of public and private HEIs. Figures 2 and 3 compare public and private sectors, by presenting the percentage of regions in each country that are served by at least one HEI.

(Figure 2 here)

\footnotetext{
${ }^{8}$ However, this detailed data are only available for the subset of RAIs. The eight educational fields are those considered in the UOE manual: Education; Humanities and Arts; Social sciences, Business and Law; Science, Mathematics and Informatics; Engineering, Manufacturing and Construction; Agriculture and Veterinary; Health and Welfare; and Services.
} 
Figure 2 confirms that almost every NUTS II region has at least one public HEI (left-hand side). By contrast, when we look at the private sector (right-hand side), private HEIs are completely inexistent in a large number of regions. When focusing on public and private RAIs, the differences between the regional coverage of both groups of HEIs are even more remarkable, as private RAIs seem to be particularly concentrated in few regions. These results suggest the existence of significant differences between the public and private higher education sectors regarding spatial diversification, with a significant geographic concentration by private HEIs.

\section{Spatial Diversification Index of Public and Private Sectors in Europe}

Figure 3 presents the results for the normalized spatial diversification index (Equation 2) for both public and private sectors. ${ }^{9}$ Focusing first on the left-hand side of the Figure, the differences between the private and public sectors appear to be clear-cut. In all countries except Austria, the value for the diversification index is superior in the public sector. This means that the regional distribution of students enrolled in RAIs is more even in the public sector than in the private one.

(Figure 3 here)

A possible explanation for this result relies on the stronger market orientation of private HEIs. Since these institutions have a stronger influence of business criteria in their academic

\footnotetext{
${ }^{9}$ The computation of the spatial diversification index was only possible for 15 countries. Cyprus, Estonia, Lithuania, Latvia, Luxembourg and Malta only have one NUTS II region, so it would be redundant to calculate the index. Also, none of the private HEIs of the Czech Republic, Greece, Ireland and Slovenia were considered to be research-active, which does not allow the computation of the index for that sector. Due to the very small number of private HEIs in Norway, UK and Switzerland, we also refrained to perform comparisons of these countries with the countries where private HEIs are considerably larger in number.
} 
decisions, they are relatively more interested in being located mainly where there is demand for higher education, and where such demand is large enough to meet their objectives. These objectives contrast with the location strategy of public authorities, which are often more concerned with assuring a greater spatial coverage across the country.

Though our focus is on RAIs, it is possible to compute the information presented in Figure 3 (left-hand side) by including all HEIs (right-hand side of the Figure). Since most non-RAIs are private, it would be possible that we could be "hiding" the effect of these private institutions and their corresponding enrolled students in the computation of spatial diversification index. Focusing on the right-hand side of Figure 3, we verify that the changes in the public sector are almost negligible, since most public institutions are classified as research-active. The changes in the private sector are more remarkable, and in fact when adding up the effect of non-RAIs, some systems become more diversified. However, we see that the overall conclusion remains - the location of enrolled students across the different regions of the country is more dispersed in the public sector than in the private sector.

Even so, the direct comparison between the levels of diversity of the public and private sectors still does not allow us to conclude whether or not the private sector is contributing to the increase in regional diversification of the national higher education systems in Europe. ${ }^{10}$ Therefore, the right-hand side of Figure 3 also presents the normalized spatial diversification index for all HEIs in both sectors. Overall, the total diversification index is not too different from the public index, which suggests that the distribution of students in the private sector does not really contribute to change the regional diversification of national higher education systems.

\footnotetext{
${ }^{10}$ Even if the private sector is focused only in a few regions (thus presenting a lower diversification index), it can still be contributing to the improvement of the country's spatial diversification index, depending on whether the private sector is "mimicking" the regional behaviour of the public sector or if, on the other hand, it is complementing the public sector by focusing on regions where the proportion of public sector's students is lower.
} 


\section{Public-Private Programmatic Diversity in Capital and Non-Capital Regions}

In our analysis we are also interested in understanding whether there are significant differences between the programmatic supply of HEIs located near the country's capital and those located far away, in the more peripheral regions. Figure 4 presents the distribution of enrolled students throughout the eight different areas of study, for public and private HEIs. Differences between private and public institutions are larger than differences between HEIs located in capital and non-capital regions (contrast Panels A-C and B-D, which are more dissimilar, with Panels A-B and C-D, where differences are not so clear-cut). Panels A and B show that the programmatic supply of public HEIs from the capital and non-capital regions are very similar. ${ }^{11}$

\section{(Figure 4 here)}

The analysis of Panels $\mathrm{C}$ and $\mathrm{D}$ of Figure 4 indicates that there are some significant differences between the patterns of supply of private HEIs located in capital and non-capital regions. Although these differences are not similar across all observed countries, there are some identifiable patterns. In the educational field of Social Science, Business and Law in particular, the proportion of enrolled students is greater in HEIs located in the capital than in HEIs located outside of the capital in some countries. We should also note that this educational field is by far the most strongly present in the private sector across Europe. An opposite pattern is shown by students enrolled in the fields of Education, Humanities and Arts, as well as in the fields of Services, which seem to be relatively more spread across noncapital regions. All other educational fields do not show a clear pattern.

\footnotetext{
${ }^{11}$ See, for instance, Teixeira et al. (2012b) for a more detailed analysis on the differences of programme diversity between the public and private sectors in a sample of countries from Eastern Europe and Latin America.
} 
The overall programmatic diversity of public and private HEIs located in the capital and non-capital regions are computed using the programmatic diversification index (Equation 3). The results obtained after normalizing the index are summarized in Figure $5 .{ }^{12}$

In line with the previous results, the differences between the sectors are more important than those observed between capital and non-capital locations. When comparing public HEIs in the non-capital regions with those near capital, it is clear that the former are somewhat more diversified than the latter. In the private sector, the pattern is similar, with HEIs from the capital regions being comparatively less diversified in most countries. When we compare public and private sectors, the same pattern emerges regardless the proximity to the country's capital: public institutions present a far more diverse supply of programmes than their private counterparts.

(Figure 5 here)

\section{Concluding Remarks}

European HEIs have been facing a period of significant change, following decades of expansion and mass access to higher education by an increasingly diverse student population. Pressured by financial constraints and by the need to respond to demands for greater accountability, higher education systems have seen a greater influence of market rules and rationales in public higher education, alongside the development of privately-funded higher education. In this article we have reflected about the relevance of those changes from a regional point of view by looking at the spatial and programmatic distribution of higher education across a sample of European countries. We have compared the spatial

\footnotetext{
${ }^{12}$ The number of countries presented for the public and private sectors varies due to the lack of RAIs in either capital or non-capital regions. Similarly to Figure 3, we have also excluded the countries with a single private institution or with a relatively very small number of private HEIs (namely UK, Switzerland and Norway).
} 
diversification patterns of both public and private sectors and our results indicate that public institutions present greater spatial diversification than their private counterparts in the majority of European countries. We have also found that in a few countries the distribution of enrolments between different educational fields seems to be less diversified in capital regions than in other regions, suggesting that in those cases the more sparsely supplied non-capital regions seem to promote a greater dispersion, while the large concentration of HEIs in capital regions favours greater programme specialization. Even so, the main divide seems to be, first of all, between public and private sectors in general, and in a lower extent between capital and non-capital regions.

These results suggest the persistence of differences in the public and private sectors, despite a growing influence of market orientation in the former. Whereas public institutions that have been established in more peripheral regions have often been asked to contribute to greater regional equity, private institutions seem to have been mainly led by calculations about potential demand and financial sustainability, which has pulled them towards more affluent and densely populated regions. Although recent trends in higher education policy have diluted this difference, especially by promoting a more managerial approach in the strategies of public institutions, the current picture indicates that the public supply of higher education seems to be still significantly shaped by the past concern in diminishing regional inequalities in the access to higher education.

Notwithstanding those differences, we are tempted to speculate to what extent those results point out future trends in the regional distribution of European higher education. With the continuous pressures upon public institutions for greater efficiency and effectiveness, especially associated with increasing financial stringency and changes in the structure of funding, public institutions are being increasingly pushed to adopt a market-like behaviour that may bring them closer the private sector. The location of universities cannot be easily 
changed, but the scope and diversity of programmes offered by each institution may change if public HEIs located in less populated regions start to close some programmes. Thus, the pattern of greater regional and programme specialization presented by private institutions, largely shaped by market forces, may give us an indication of future trends in the public sector.

Moreover, when we compared the results for the group of research-active institutions and the overall population, the main results persisted, though the more research intensive institutions seem to be more concentrated both in their programmatic supply and their regional dispersion. On the one hand, this suggests that, under tighter competition, more research intensive institutions may refrain from expanding their activities in peripheral areas, since the demand for their educational and research services is more limited. On the other hand, this also suggests that if public policy intends to have any effectiveness in bringing R\&D activities to more peripheral regions, it needs to strengthen the public mission of HEIs, rather than its business orientation. Thus, governments need to think about incentives that may attract more public institutions to those regions and reward the already existing ones for a greater regional engagement.

The analysis presented in this article has some limitations and needs to be extended in further research. Namely, we need to develop a longitudinal approach that may help us to identify the dynamics of regional diversification over time of both public and private higher education sectors. This will be important to confirm whether the patterns of behaviour sketched in this analysis are robust and to what extent stronger marketization may be changing the regional distribution of public supply, possibly making it more similar to private supply. Moreover, subsequent research should consider a more in-depth analysis of these issues, also by exploring in more detail the regional effects of marketization and competition and assess the effectiveness of different policy strategies in promoting a less unequal regional 
distribution of higher education in Europe. Since market forces are likely to continue to play an important role in European higher education, the analysis of its potential impacts need to be addressed more extensively, notably from a regional point of view. We hope that the exploratory analysis developed in this article may stimulate others to contribute to this purpose.

\section{References}

Amaral, A., Jones, G., Karseth (Eds.). (2002). Governing Higher Education: National Perspectives on Institutional Governance (Vol. 2). Dordrecht/Boston/London: Kluwer Academic Publishers.

Amaral, A., V.L. Meek and I.M. Larsen (eds). (2003) The Higher Education Managerial Revolution? Dordrecht: Kluwer.

Andersson, R., Quigley, J. and Wilhelmson, M. (2004). "University Decentralization as Regional Policy: The Swedish Experiment. Journal of Economic Geography, Vol. 4, pp. 371-388.

Altbach, P. (1999) Private Prometheus: Private Higher Education and Development in the 21st Century, (Westport (CT), Greenwood Press).

Barr, N. (2004) The Economics of the Welfare State. (Oxford: Oxford University Press).

Bok, Derek (2003) Universities in the Marketplace; Princeton: Princeton University Press

Charles, D. (2006). "Universities and Key Knowledge Infrastructures in Regional Innovation Systems. Innovation: The European Journal of Social Science Research, Vol. 19, No. 1, pp. 117-130.

De Boer, H., J. Enders and B. Jongbloed. (2009). "Market Governance in Higher Education", in in Kehm; Huisman and Stensaker (eds) The European Higher Education area: Perspectives on a Moving Target, Sense Publishers, pp. 61-78

EUMIDA (2010) "Final Study Report", available at http://ec.europa.eu/research/era/docs/en/eumida-finalreport.pdf, accessed $12^{\text {th }}$ November 2012.

Geiger, R. and Sá, C. (2008) Tapping the Riches of Science - Universities and the Promise of Economic Growth (Cambridge (MA): Harvard University Press).

Geiger, R. (1986) Private Sectors in Higher Education (Ann Arbor: The University of Michigan Press).

Geiger, Roger (2004) Knowledge and Money; Stanford UP

Geuna, A. (2001) The Changing Rationale for European University Research Funding: Are There Negative Unintended Consequences?, Journal of Economic Issues, Vol. 35, No. 3, pp. 607-632

Hazelkorn, E. 2007. The Impact of League Tables and Ranking Systems on Higher Education Decision Making. Higher Education Management and Policy, 19(2), pp. 87-110. 
Herbst, M. (2006) Performance Based Funding; Springer: Dordrecht

Johnstone, B. and Marcucci P. (2010) Financing Higher Education Worldwide: Who Pays? Who Should Pay? (Baltimore (MD): The John Hopkins University Press).

Jongbloed, B. (2006), Strengthening consumer choice in higher education. In: Teixeira, P.N. et al. (eds.), Cost sharing and accessibility in higher education. Dordrecht: Springer, pp. 19-50.

Kehm B. (2006). The German "Initiative for Excellence" and the Issue of Ranking. International Higher Education, 44, 20-22.

Le Grand, J. (2007) The Other Invisible Hand: Delivering Public Services through Choice and Competition (Princeton (NJ): Princeton University Press).

Le Grand, J., Bartlett, W., (eds.) (1993) Quasi-markets and social policy. Macmillan Press, Basingstoke, UK

Levy, D. (2006) “An Introductory Global Overview: The Private Fit to Salient Higher Education Tendencies”. PROPHE Working Paper No. 7.

Levy, D. (2002) “Unanticipated Development: Perspectives on Private Higher Education's Emerging Roles”. PROPHE Working Paper No. 1.

Middlehurst, R. and Teixeira, P. (2012) Governance within the EHEA: dynamic trends, common challenges, and national particularities, in Peter Scott, Adrian Curaj, Lazar Vlasceanu, and Lesley Wilson (eds.) European Higher Education at the Crossroads: Between the Bologna Process and National Reforms, Springer, Vol. 2, 527-551

Morphew, C. and Eckel P. (eds) (2009), Privatizing the Public University - Perspectives from across the Academy (Baltimore: John Hopkins Press).

Neave, G. (2012) The Evaluative State, Institutional Autonomy and Re-engineering Higher Education in Western Europe (London and New York: Palgrave/MacMillan).

Neave, G. and Van Vught F. (eds) (1991), Prometheus Bound: The Changing Relationship Between Government and Higher Education in Western Europe (London: Pergamon Press).

Palfreyman, D. and Tapper, T. (eds.) (2009) Structuring Mass Higher Education: The Role of Elite Institutions (New York and Abingdon: Routledge).

Pepall, L., Richards, D. and Norman, G. (2008) Industrial Organization - Contemporary Theory and Empirical Applications, 4th edn, (Malden, MA: Wiley-Blackwell).

Pollitt, C. and Bouckaert, G. (2011) Public Management Reform (Oxford: Oxford University Press).

Pollitt, C., Bouckaert, C. (2009) Continuity and Change in Public Policy and Management, Cheltenham: Edward Elgar

Readings, B. (1996) The University in Ruins; Harvard University Press

Regini, M. (2011) European Universities and the Challenge of the Market: A Comparative Analysis (Aldershot: Edward Elgar).

Rossi, F. (2009), "Increased competition and diversity in higher education: an empirical analysis of the Italian university system", Higher Education Policy, Vol. 22, pp. 389-413.

Rubiralta, M. and Delgado, L. (2010). Developing International Campus of Excellence in Spain. CELE Exchange 2010/4, OECD. 
Scott, P. (1995) The Meanings of Mass Higher Education (Milton Keynes: Open University Press).

Shattock, M. (Ed.). (2008). Entrepreneurialism in Universities and the Knowledge Economy: Diversification and Organizational Change in European Higher Education. Maidenhead: McGraw Hill, Society for Research into Higher Education, Open University Press.

Slantcheva, S. and Levy D. (Eds) (2007) Private Higher Education in Post-Communist Europe - In Search for Legitimacy (New York: Palgrave/MacMillan).

Slaughter, S. and Leslie L. (1997) Academic Capitalism (Baltimore (MD): The Johns Hopkins University Press).

Sterlacchini, A. (2008). "R\&D, Higher Education and Regional Growth: Uneven Linkages among European Regions. Research Policy, Vol. 37, pp. 1096-1107.

Teixeira, P. (2009) “Privatization and Mass Higher Education - Some Lessons from Experience?". Higher Education to 2030: Vol. 2: Globalisation, CERI - Centre for Educational Research and Innovation, Directorate of Education, Paris: OECD.

Teixeira, P., Rocha, V., Biscaia, R. and Cardoso, M. (2012a) "Competition and diversity in higher education: an empirical approach to specialization patterns of Portuguese institutions". Higher Education, Vol. 63, No.3, pp. 337-352.

Teixeira, P., Rocha, V., Biscaia, R. and Cardoso, M. (2012b) "Myths, Beliefs and Realities: Public-Private Competition and Program Diversification in Higher Education”. Journal of Economic Issues, Vol. 46, No. 3, pp. 683-704.

Teixeira, P., Dill, D., Amaral A. and Jongbloed B. (eds) (2004) Markets in higher education (Amsterdam: Kluwer).

Tierney, W. J. (Ed.) (1998) The Responsive University: Restructuring for High Performance; Baltimore, John Hopkins Press.

Trow, M. (2010) Twentieth-Century Higher Education - Elite to Mass to Universal (Baltimore (MD): John Hopkins Press).

Van Vught, F. (ed) (1989) Governmental Strategies and Innovations in Higher Education (London: Jessica Kingsley).

Weisbrod, B., Jeffrey A., Ballou P. and Asch E. (2008) Mission and Money: Understanding the University (Cambridge: Cambridge University Press).

Wells, P., Sadlak J. and L. Vlăsceanu (Eds) (2007) The Rising Role and Relevance of Private Higher Education in Europe (Bucharest: UNESCO-CEPES).

Williams, G. (1991) “The Many Faces of Privatisation”. Higher Education Management, Vol. 8, pp. 39-56.

Winston, Gordon C (1999), "Subsidies, hierarchy and peers: The awkward economics of higher education" Journal of Economic Perspectives; 13, 1; pp. 13-36. 
Table 1. Relative weights of Public and Private Sectors in RAIs dataset - Capital versus Non-Capital Regions*

\begin{tabular}{|c|c|c|c|c|c|c|c|c|c|c|c|c|c|c|c|c|c|c|c|c|c|c|c|c|}
\hline \multirow{4}{*}{$\begin{array}{l}\text { Country } \\
\text { Austria }\end{array}$} & \multicolumn{8}{|c|}{ Research Active Institutions (RAIs) } & \multicolumn{8}{|c|}{ Capital Regions } & \multicolumn{8}{|c|}{ Non-Capital Regions } \\
\hline & \multicolumn{4}{|c|}{ Public RAIs } & \multicolumn{4}{|c|}{ Private RAIs } & \multicolumn{4}{|c|}{ Public RAIs } & \multicolumn{4}{|c|}{ Private RAIs } & \multicolumn{4}{|c|}{ Public RAIs } & \multicolumn{4}{|c|}{ Private RAIs } \\
\hline & \multicolumn{2}{|c|}{ Nr. HEIs } & \multicolumn{2}{|c|}{$\begin{array}{l}\text { Enrolled } \\
\text { Students }\end{array}$} & \multicolumn{2}{|c|}{ Nr. HEIs } & \multicolumn{2}{|c|}{$\begin{array}{l}\text { Enrolled } \\
\text { Students }\end{array}$} & \multicolumn{2}{|c|}{ Nr. HEIs } & \multicolumn{2}{|c|}{$\begin{array}{l}\text { Enrolled } \\
\text { Students } \\
\end{array}$} & \multicolumn{2}{|c|}{ Nr. HEIs } & \multicolumn{2}{|c|}{$\begin{array}{l}\text { Enrolled } \\
\text { Students } \\
\end{array}$} & \multicolumn{2}{|c|}{ Nr. HEIs } & \multicolumn{2}{|c|}{ Enrolled Students } & \multicolumn{2}{|c|}{ Nr. HEIs } & \multicolumn{2}{|c|}{$\begin{array}{l}\text { Enrolled } \\
\text { Students } \\
\end{array}$} \\
\hline & 51 & $75 \%$ & 263363 & $\mathbf{9 8 \%}$ & 17 & $25 \%$ & 6768 & $3 \%$ & 18 & $72 \%$ & 136165 & $\mathbf{9 8 \%}$ & 7 & $28 \%$ & 2788 & $2 \%$ & 33 & $77 \%$ & 127198 & $97 \%$ & 10 & $23 \%$ & 3980 & $3 \%$ \\
\hline Belgium $^{\mathrm{a}}$ & 66 & $77 \%$ & 155226 & $57 \%$ & 19 & $22 \%$ & 109849 & $41 \%$ & 26 & $87 \%$ & 29091 & $67 \%$ & 4 & $13 \%$ & 14553 & $33 \%$ & 45 & $75 \%$ & 123966 & $57 \%$ & 15 & $25 \%$ & 95296 & $43 \%$ \\
\hline Bulgaria & 37 & $95 \%$ & 187493 & $90 \%$ & 2 & $5 \%$ & 21036 & $10 \%$ & 24 & $96 \%$ & 94209 & $90 \%$ & 1 & $4 \%$ & 10221 & $10 \%$ & 13 & $93 \%$ & 93284 & $90 \%$ & 1 & $7 \%$ & 10815 & $10 \%$ \\
\hline Switzerland & 34 & $94 \%$ & 171673 & $99 \%$ & 2 & $6 \%$ & 922 & $1 \%$ & 5 & $83 \%$ & 52336 & $99 \%$ & 1 & $17 \%$ & 268 & $1 \%$ & 34 & $94 \%$ & 119337 & $99 \%$ & 2 & $6 \%$ & 655 & $1 \%$ \\
\hline Cyprus & 3 & $43 \%$ & 6144 & $44 \%$ & 4 & $57 \%$ & 7836 & $56 \%$ & n.a. & n.a & n.a & n.a & n.a & n.a & n.a & n.a & n.a & n.a & n.a & n.a & n.a & n.a & n.a & n.a \\
\hline Czech Rep. & 26 & $100 \%$ & 325692 & $100 \%$ & 0 & $0 \%$ & 0 & $0 \%$ & 9 & $100 \%$ & 114818 & $100 \%$ & 0 & $0 \%$ & 0 & $0 \%$ & 17 & $100 \%$ & 210874 & $100 \%$ & 0 & $0 \%$ & 0 & $0 \%$ \\
\hline Germany & 250 & $82 \%$ & 1884681 & $97 \%$ & 55 & $18 \%$ & 52548 & $3 \%$ & 15 & $79 \%$ & 129189 & $97 \%$ & 4 & $21 \%$ & 3495 & $3 \%$ & 246 & $81 \%$ & 1755492 & $97 \%$ & 58 & $19 \%$ & 49063 & $3 \%$ \\
\hline Estonia & 6 & $86 \%$ & 44922 & $97 \%$ & 1 & $14 \%$ & 1590 & $3 \%$ & n.a & n.a & n.a & n.a & n.a & n.a & n.a & n.a & n.a & n.a & n.a & n.a & n.a & n.a & n.a & n.a \\
\hline Spain $^{\mathrm{b}}$ & 47 & n.a. & 1167901 & n.a. & n.a. & n.a. & n.a. & n.a. & 6 & $100 \%$ & 210484 & $100 \%$ & 0 & $0 \%$ & 0 & $0 \%$ & 41 & $100 \%$ & 957417 & $100 \%$ & 0 & $0 \%$ & 0 & $0 \%$ \\
\hline Finland & 49 & $100 \%$ & 296569 & $100 \%$ & 0 & $0 \%$ & 0 & $0 \%$ & 26 & $100 \%$ & 145940 & $100 \%$ & 0 & $0 \%$ & 0 & $0 \%$ & 23 & $100 \%$ & 150629 & $100 \%$ & 0 & $0 \%$ & 0 & $0 \%$ \\
\hline Greece & 40 & $100 \%$ & 579150 & $100 \%$ & 0 & n.a & 0 & n.a. & 11 & $100 \%$ & 213965 & $100 \%$ & 0 & $0 \%$ & 0 & $0 \%$ & 29 & $100 \%$ & 365185 & $100 \%$ & 0 & $0 \%$ & 0 & $0 \%$ \\
\hline Hungary & 29 & $50 \%$ & 328607 & $88 \%$ & 29 & $\mathbf{5 0 \%}$ & 43445 & $12 \%$ & 14 & $44 \%$ & 137244 & $81 \%$ & 18 & $56 \%$ & 32175 & $19 \%$ & 15 & $\mathbf{5 8 \%}$ & 191363 & $94 \%$ & 11 & $42 \%$ & 11270 & $6 \%$ \\
\hline Ireland & 21 & $100 \%$ & 155036 & $100 \%$ & 0 & $0 \%$ & 0 & $0 \%$ & 15 & $100 \%$ & 121164 & $100 \%$ & 0 & $0 \%$ & 0 & $0 \%$ & 6 & $100 \%$ & 33872 & $100 \%$ & 0 & $0 \%$ & 0 & $0 \%$ \\
\hline Italy & 67 & $83 \%$ & 1832956 & $94 \%$ & 14 & $17 \%$ & 120336 & $6 \%$ & 6 & $55 \%$ & 241082 & $\mathbf{8 8 \%}$ & 5 & $45 \%$ & 33720 & $13 \%$ & 61 & $87 \%$ & 1591874 & $95 \%$ & 9 & $13 \%$ & 86616 & $5 \%$ \\
\hline Lithuania & 15 & $94 \%$ & 139445 & n.a. & 1 & $6 \%$ & cf. & n.a. & n.a & n.a & n.a & n.a & n.a & n.a & n.a & n.a & n.a & n.a & n.a & n.a & n.a & n.a & n.a & n.a \\
\hline Luxembourg & 1 & $100 \%$ & 3526 & $100 \%$ & 0 & $0 \%$ & 0 & $0 \%$ & n.a & n.a & n.a & n.a & n.a & n.a & n.a & $\mathrm{n} . \mathrm{a}$ & $\mathrm{n} . \mathrm{a}$ & n.a & n.a & $\mathrm{n} . \mathrm{a}$ & n.a & n.a & n.a & n.a \\
\hline Latvia & 15 & $75 \%$ & 67939 & $75 \%$ & 5 & $25 \%$ & 22971 & $25 \%$ & n.a & n.a & n.a & n.a & n.a & n.a & n.a & n.a & n.a & n.a & n.a & n.a & n.a & n.a & n.a & n.a \\
\hline Malta & 1 & $100 \%$ & 9508 & $100 \%$ & 0 & $0 \%$ & 0 & $0 \%$ & n.a & n.a & n.a & n.a & n.a & n.a & n.a & n.a & n.a & n.a & n.a & n.a & n.a & n.a & n.a & n.a \\
\hline Netherlands & 54 & $92 \%$ & 624520 & $99 \%$ & 5 & $9 \%$ & 5031 & $1 \%$ & 6 & $100 \%$ & 94123 & $100 \%$ & 0 & $0 \%$ & 0 & $0 \%$ & 48 & $91 \%$ & 530397 & $99 \%$ & 5 & $9 \%$ & 5031 & $1 \%$ \\
\hline Norway & 45 & $98 \%$ & 196029 & 93\% & 1 & $2 \%$ & 14544 & $7 \%$ & 13 & $93 \%$ & 57681 & $80 \%$ & 1 & $7 \%$ & 14544 & $20 \%$ & 32 & $100 \%$ & 138348 & $100 \%$ & 0 & $0 \%$ & 0 & $0 \%$ \\
\hline Poland & 87 & $96 \%$ & 1176158 & $97 \%$ & 4 & $4 \%$ & 41718 & $3 \%$ & 13 & $81 \%$ & 189438 & $89 \%$ & 3 & $19 \%$ & 23167 & $11 \%$ & 74 & $99 \%$ & 986720 & $98 \%$ & 1 & $1 \%$ & 18551 & $2 \%$ \\
\hline Portugal & 14 & $78 \%$ & 176082 & $86 \%$ & 4 & $22 \%$ & 28175 & $14 \%$ & 4 & $57 \%$ & 65280 & $73 \%$ & 3 & $43 \%$ & 23824 & $27 \%$ & 11 & $79 \%$ & 110802 & $81 \%$ & 3 & $21 \%$ & 25557 & $19 \%$ \\
\hline Romania & 45 & $79 \%$ & 598635 & $65 \%$ & 12 & $21 \%$ & 326885 & $35 \%$ & 10 & $56 \%$ & 92301 & $48 \%$ & 8 & $44 \%$ & 100668 & $52 \%$ & 45 & 75\% & 506334 & $69 \%$ & 15 & $25 \%$ & 226217 & $31 \%$ \\
\hline Sweden & 36 & $88 \%$ & 338795 & 93\% & 5 & $12 \%$ & 24896 & $7 \%$ & 13 & $81 \%$ & 67924 & $96 \%$ & 3 & $19 \%$ & 2979 & $4 \%$ & 23 & $92 \%$ & 270871 & $93 \%$ & 2 & $8 \%$ & 21917 & $7 \%$ \\
\hline Slovenia & 4 & $100 \%$ & 90862 & $100 \%$ & 0 & $0 \%$ & 0 & $0 \%$ & 3 & $100 \%$ & 67499 & $100 \%$ & 0 & $0 \%$ & 0 & $0 \%$ & 1 & $100 \%$ & 23363 & $100 \%$ & 0 & $0 \%$ & 0 & $0 \%$ \\
\hline Slovakia & 23 & $70 \%$ & 201926 & $87 \%$ & 10 & $30 \%$ & 31010 & $13 \%$ & 6 & $60 \%$ & 21295 & $61 \%$ & 4 & $40 \%$ & 13748 & $39 \%$ & 20 & $74 \%$ & 151590 & $90 \%$ & 7 & $26 \%$ & 17262 & $10 \%$ \\
\hline UK & 147 & $99 \%$ & 2245416 & $100 \%$ & 1 & $1 \%$ & 985 & $0 \%$ & 28 & $100 \%$ & 252462 & $100 \%$ & 0 & $0 \%$ & 0 & $0 \%$ & 120 & 99\% & 2021995 & $100 \%$ & 1 & $1 \%$ & 985 & $0 \%$ \\
\hline
\end{tabular}

*Data from EUMIDA project (EUMIDA, 2010). n.a. = not available; cf. = confidential; ${ }^{a}$ the number of students reported for the public sector in Belgium (155226) only regards 24 public HEIs. There are 42 public HEIs in Belgium that do not report the number of enrolled students, due to some data availability restrictions. These 42 public HEIs are also included in RAIs. ${ }^{b}$ Spain did not report any data on private institutions. Cyprus, Estonia, Lithuania, Luxembourg, Latvia and Malta only have one NUTS II region, which hinders the regional analysis. Some HEIs are present in more than one region, and we assumed a full HEI count for the region, which resulted in the duplication of some HEIs in both capital and non-capital regions. Similarly, their enrolled students were evenly distributed between the regions the HEIs are located in. 
Figure 1. Relative weight of RAIs in total enrolments
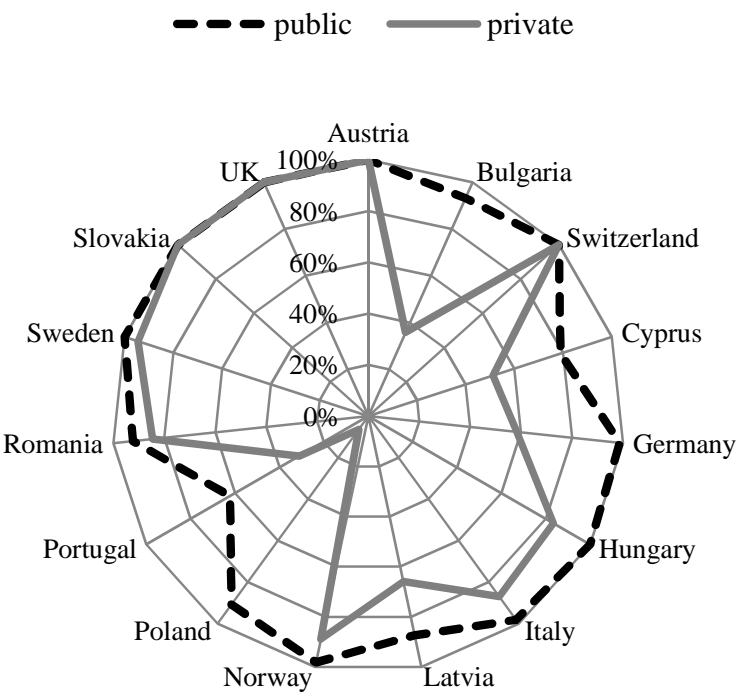
Figure 2. Proportion of NUTS II regions with:

at least one public HEI

$\square$ Research Active Institutions

All Institutions

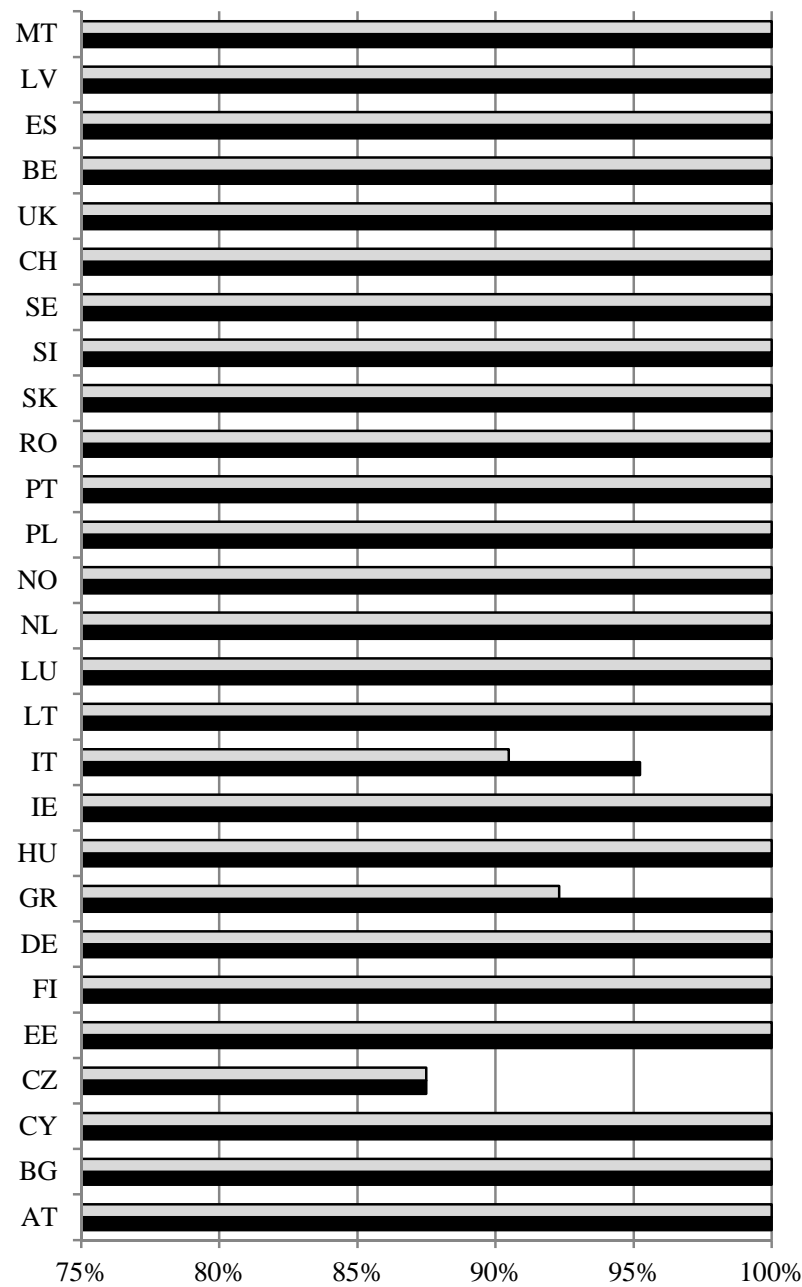

at least one private HEI

$\square$ Research Active Institutions

-All Institutions

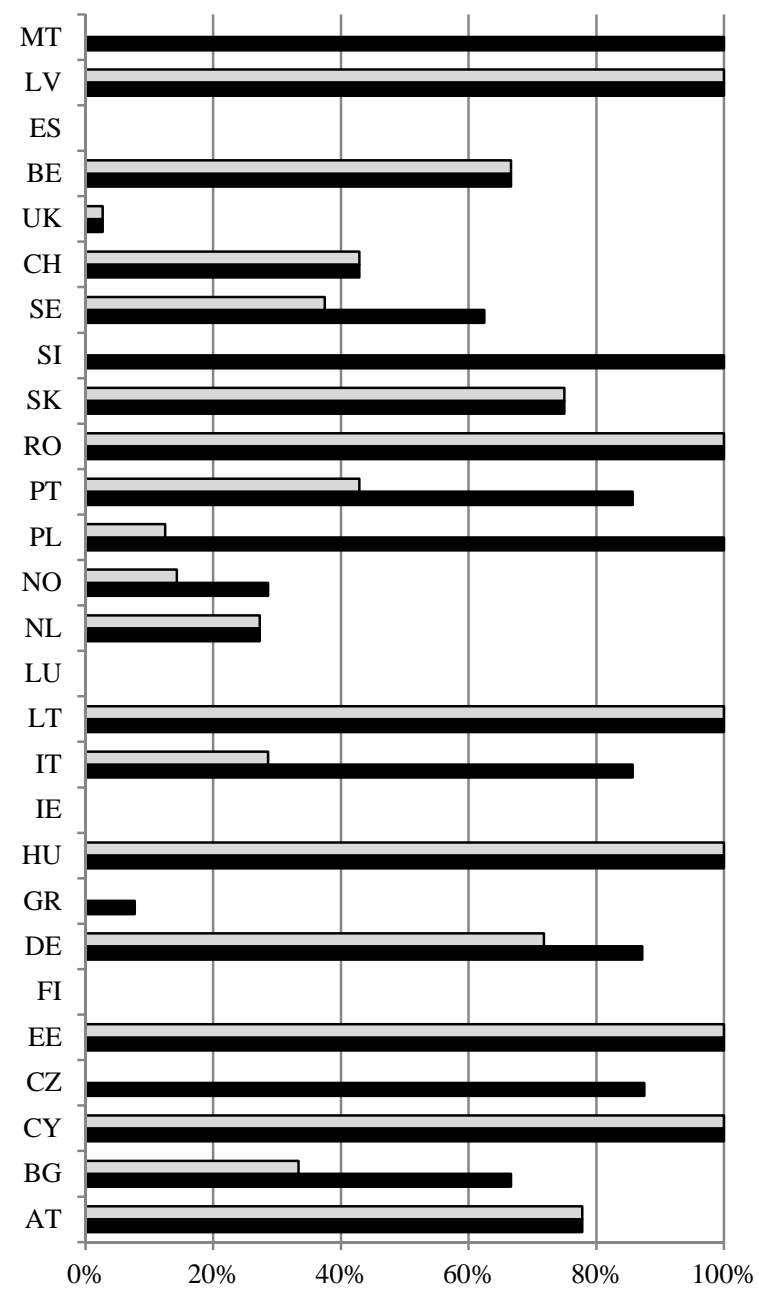

AT - Austria; BE - Belgium; BG - Bulgaria; CH - Switzerland; CY - Cyprus; CZ - Czech Rep.; DE - Germany; EE Estonia; ES - Spain; FI - Finland; GR - Greece; HU - Hungary; IE - Ireland; IT - Italy; LT - Lithuania; LU Luxembourg; LV - Latvia; MT - Malta; NL - Netherlands; NO - Norway; PL - Poland; PT - Portugal; RO - Romania; SE - Sweden; SK - Slovakia; UK - United Kingdom. 
Figure 3. Normalized Spatial Diversification Index (NUTS II regions)

\section{RAIs}

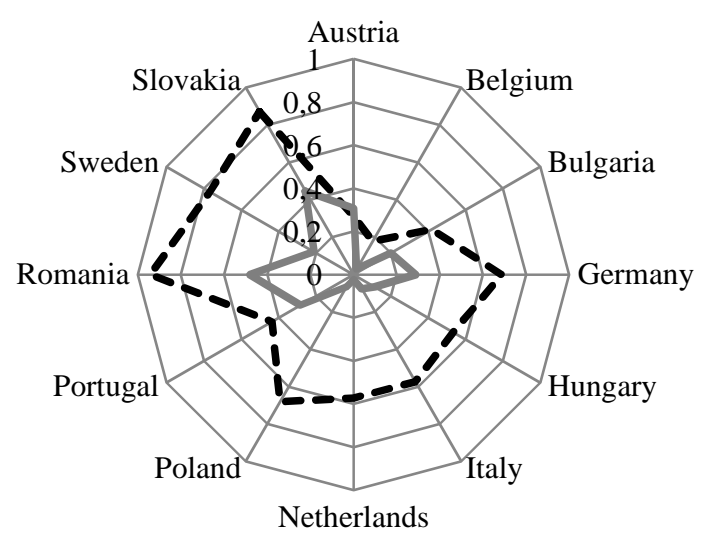

- - Public Private
All HEIs

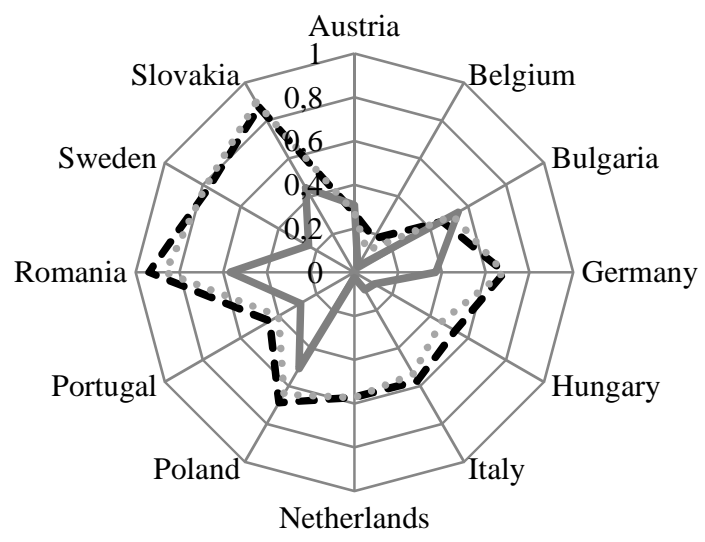

- - Public Private $\ldots$ Total 
Figure 4. Distribution of enrolled students by educational field in the Public and Private Sectors*

A. Public Sector - Capital Region

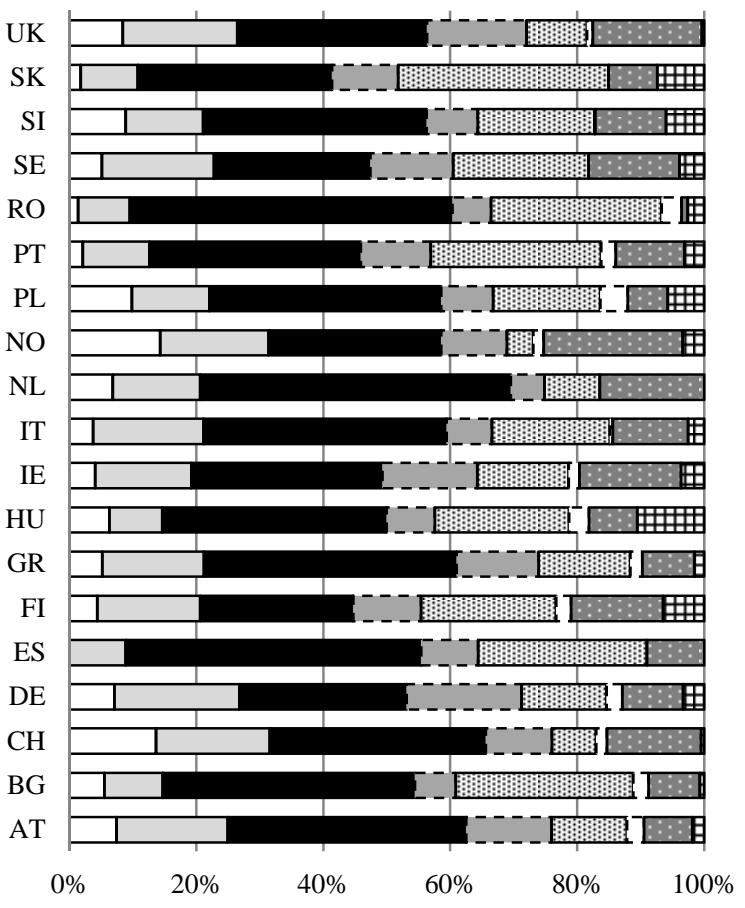

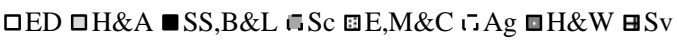

C. Private Sector - Capital Region

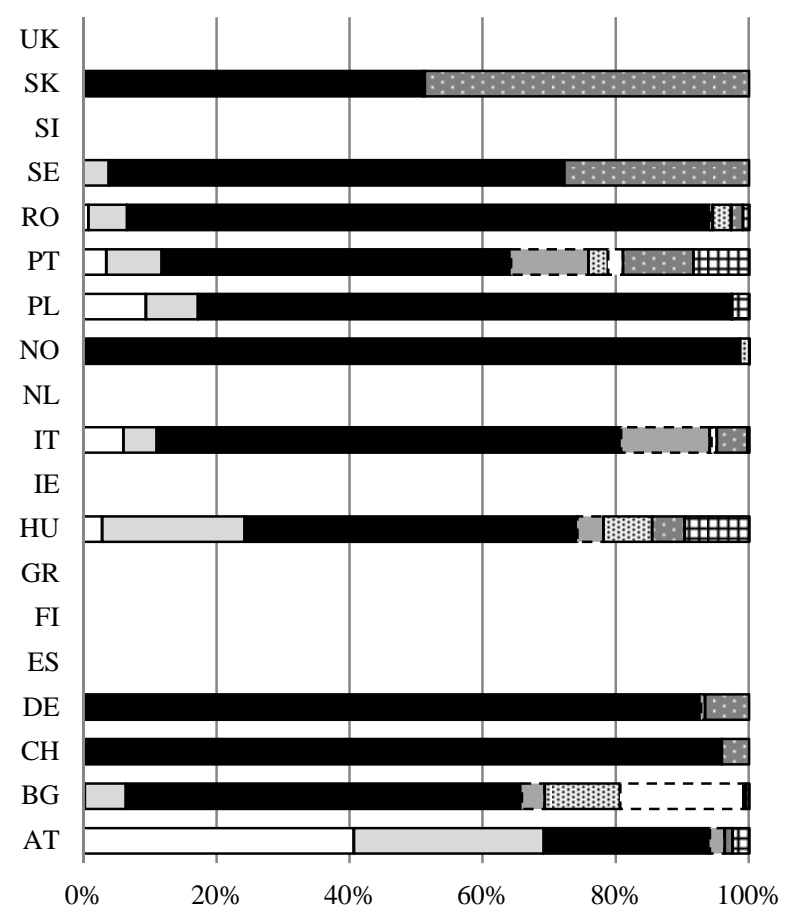

口ED $\square \mathrm{H} \& \mathrm{~A} \backsim \mathrm{SS}, \mathrm{B} \& \mathrm{~L} \backsim \mathrm{Sc} \boxplus \mathrm{E}, \mathrm{M} \& \mathrm{C} \backsim \mathrm{Ag} \square \mathrm{H} \& \mathrm{~W} \boxplus \mathrm{Sv}$
B. Public Sector - Out of the Capital Region

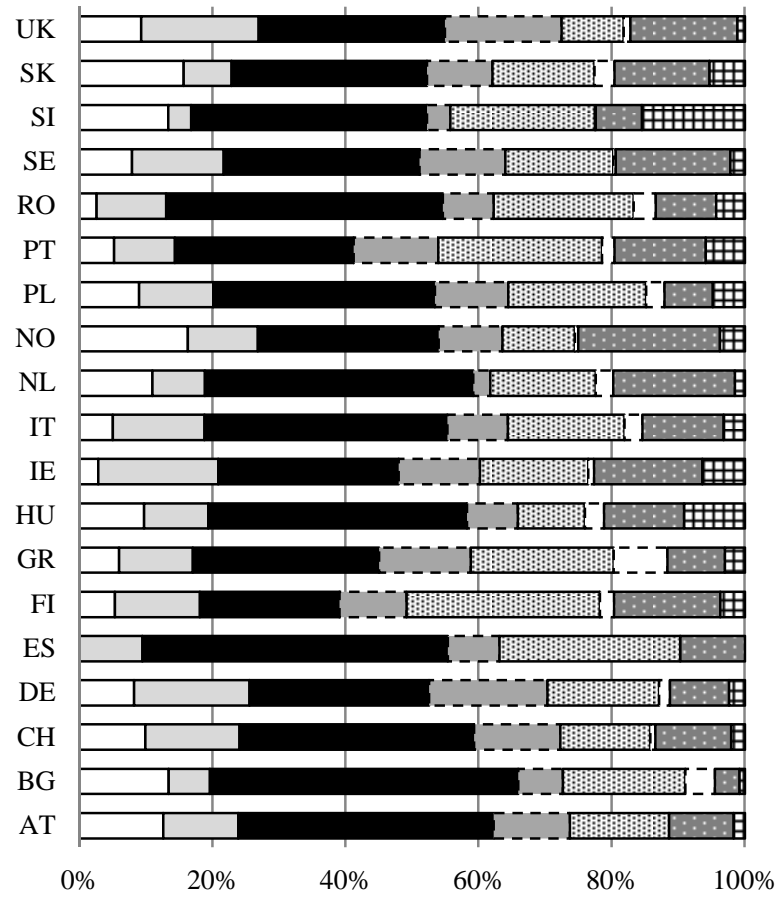

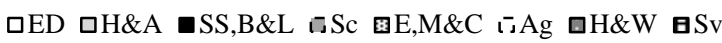

D. Private Sector - Out of the Capital Region

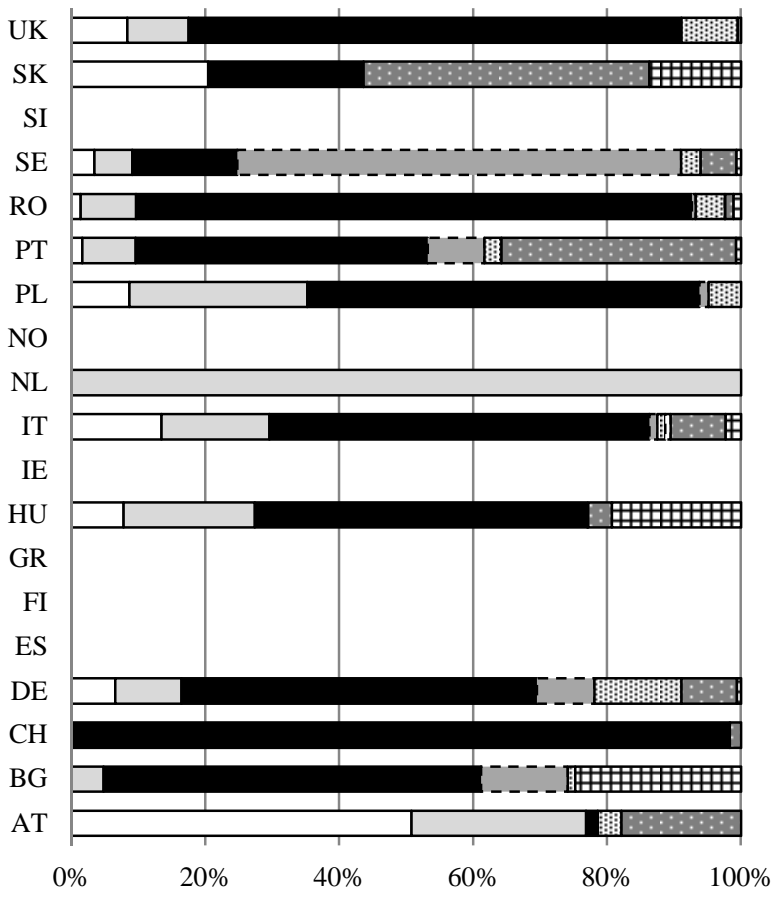

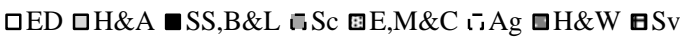

* Research Active Institutions; AT - Austria; BE - Belgium; BG - Bulgaria; CH - Switzerland; CY - Cyprus; CZ - Czech Rep.; DE Germany; EE - Estonia; ES - Spain; FI - Finland; GR - Greece; HU - Hungary; IE - Ireland; IT - Italy; LT - Lithuania; LU Luxembourg; LV - Latvia; MT - Malta; NL - Netherlands; NO - Norway; PL - Poland; PT - Portugal; RO - Romania; SE - Sweden; SK Slovakia; UK - United Kingdom. 
Figure 5. Programmatic diversity of HEIs located in capital and non-capital regions (public versus private sectors) $*$

Public Sector

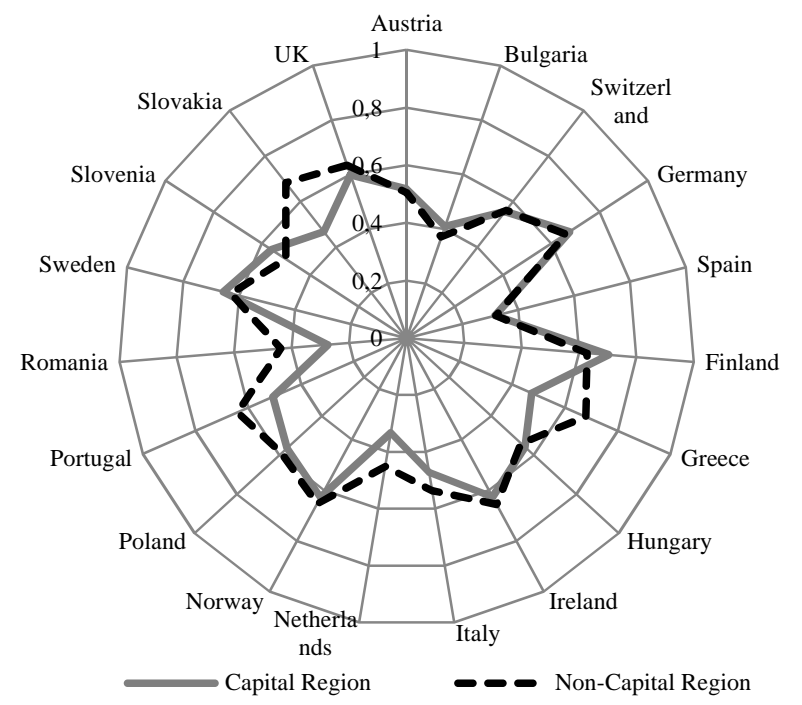

Private Sector

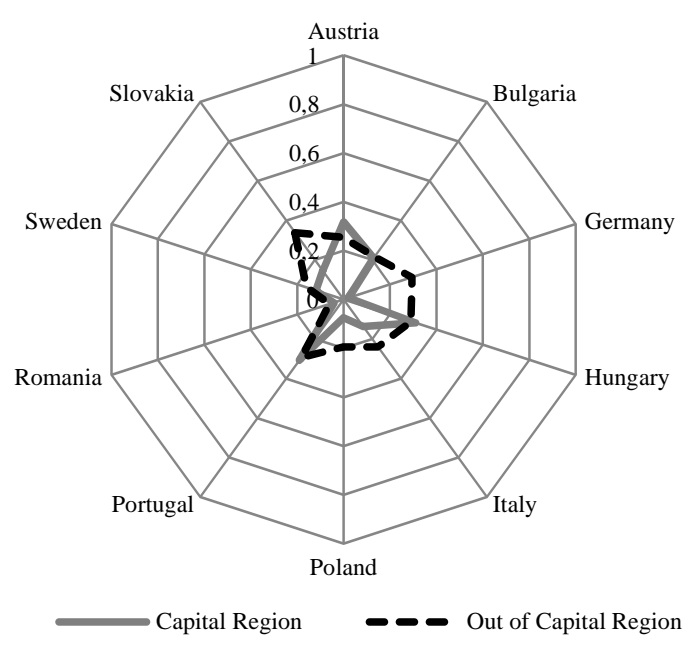

* Research Active Institutions

ES - Spain; FI - Finland; GR - Greece; HU - Hungary; IE - Ireland; IT - Italy; LT - Lithuania; LU - Luxembourg; LV Latvia; MT - Malta; NL - Netherlands; NO - Norway; PL - Poland; PT - Portugal; RO - Romania; SE - Sweden; SK Slovakia; UK - United Kingdom. 


\section{ACKNOWLEDGEMENTS}

We are very grateful to the two anonymous referees, whose comments were extremely helpful in improving this paper. All the remaining errors and omissions are our responsibility. Some of the data included in this paper were collected in the framework of the EUMIDA project. CIPES and CIIMAR are funded by FCT - The Portuguese National Foundation for Science and Technology of the Ministry of Science, Technology, and Higher Education. 